\title{
Gingival Veneers: A Case Series for Treatment of Multiple Gingival Recession and Black Triangles.
}

\author{
Dr Priya Vijay Thakkar ${ }^{1}$, Dr Amol Beldar ${ }^{2}$, Dr Supriya Murkute ${ }^{3}$, \\ Dr Mitali Thamke ${ }^{4}$ \\ PG Student Of Periodontology; Mgvs KBH Dental College And Hospital Nashik. ${ }^{l}$ \\ Reader And Guide Of Periodontology; Mgvs KBH Dental College And Hospital Nashik ${ }^{2}$ \\ PG Student Of Periodontology; Mgvs KBH Dental College And Hospital Nashik ${ }^{3}$. \\ PG Student Of Periodontology; Mgvs KBH Dental College And Hospital Nashik ${ }^{4}$.
}

\begin{abstract}
Gingival and periodontal disease leads to recession, black triangles, soft tissue defect in the esthetic region. For these problems non surgical and surgical treatment modalities have been reported. When large volumes of tissue are missing with interdental papilla loss, treatment methods such as reconstruction of papilla are not possible. The other surgical treatment modalities like mucogingival surgeries are unpopular because of long healing time, discomfort and surgical costs. The reconstruction of these areas with prosthesis like gingival veneer can be useful to correct these deformities that remain after the control of periodontal diseases, especially in the maxillary anterior esthetic region. This case series of 3 patients aims to revisit the gingival veneer, which highlights a clinical situation where the gingival veneer prosthesis helped in achieving the optimum esthetics and patient satisfaction, thus proving to be a feasible and simple treatment modality.
\end{abstract}

Keywords: Gingival Veneers, Gingival Recession, Interdental Papilla, Esthetic.

\section{Introduction}

Periodontal disease leads to loss of alveolar bone, apical migration of the gingival margin which leads to denuded root surface resulting in dentinal hypersensitivity. In severe forms of periodontitis it leads to loss of interdental bone and due to which it leads to loss of interdental papilla because of which black triangles are formed. Black triangles are rated as the third most disliked esthetic problem below caries and crown margins. ${ }^{[1]}$ Such interdental spaces may also result in phonetic problems due to escape of air. ${ }^{[2]}$ Isolated gingival recessions can be corrected by various surgical root coverage procedures such as coronally advance flap procedure, laterally displaced flap procedure and many other procedures but these procedures can only be used for isolated recession. In case of multiple recession double lateral sliding procedure, bridge flap procedure etc are used to cover multiple gingival recession but all these procedure require minimum width of attach gingiva for root coverage. In cases of moderate to severe periodontitis where gingival recession can be generalized and very extensive then it cannot be corrected by surgical root coverage procedures. Thus the alternative for such a clinical situation is gingival prosthesis.

Gingival prostheses (Gingival veneer) may be used to replace tissues lost due to periodontal diseases, surgical gingival procedures, trauma, ridge resorption or traumatic tooth extraction all of which can result in open inter dental spaces, elongated clinical crowns, phonetic problems as well as unanticipated expectoration during speech. ${ }^{[2]}$ A gingival veneer is defined as a prosthesis worn in the labial aspect of the dental arch, which aims to restore the mucogingival contour and esthetics in areas where periodontal tissues are deficient. ${ }^{[3]}$ Gingival veneers were first introduced in 1955 by Emslie and were used to mask the unesthetic appearance of gingival recession in a patient who underwent a gingivectomy. ${ }^{[4]}$ L'Estrange et al. in year 1970 reported on a number of patients that had worn gingival veneers for over 3 years. ${ }^{[5]}$ Porcelains, pink auto cure and heat-cured acrylics, composite resins and thermoplastic acrylics, as well as silicone-based soft materials are being used to make gingival veneers. A good case selection, with adequate oral hygiene is a key factor in the success of the gingival veneer.

The indications for gingival prosthesis are: ${ }^{[6]}$

1. Gingival recession with root exposure and open interdental spaces due to loss of papillae after periodontal disease or post-periodontal treatment therapy.

2. Provisional coverage prior to definite restorations (Temporary splint).

3. As a gingival augmentation for implant supported prosthesis.

4. When there is proclination of teeth along with mild recession.

5. As an interim measure in cases where final treatment planning is delayed. 
Contraindications of gingival prosthesis include: ${ }^{[6]}$

1. Poor or unstable periodontal health.

2. Poor oral hygiene.

3. High caries activity.

4. Known allergy to silicone.

5. Heavy smokers.

Case I:

\section{Case series}

A 45-year old female patient visited the Department of Periodontics, with the chief complaint of increased spaces between teeth and elongated teeth in upper anterior right region of the jaw. Diagnoses of a case of generalized chronic periodontitis was made. She had undergone periodontal flap therapy as a result of which had gingival recession and abrasion defect in upper anterior region. Surgical correction to cover the recession and the inter-dental black triangles was not possible and hence the decision to fabricate a gingival veneer was established.(Figure- 1a,1b)

Case II:

A 50-year old male patient visited the Department of Periodontics, with the chief complaint of mobility, increase in spacing and brownish discoloration of teeth due to exposure if the denuded root surface in upper anterior and increased spaces between teeth and increased visibility of teeth in upper anterior right region of the jaw. He was diagnosed as a case of generalized chronic periodontitis. He had undergone periodontal flap therapy as a result of which had gingival recession and black triangles in upper anterior region. Surgical correction to cover the recession and the interdental black triangles was not possible and hence the decision to fabricate a gingival veneer was established.(Figure- $2 \mathrm{a}, 2 \mathrm{~b}$ )

\section{Case III:}

A 49-year old female patient visited the Department of Periodontics, with the chief complaint of bleeding gums, food impaction, mobility with upper anterior and increased spaces between teeth and increased visibility of teeth in upper anterior right region of the jaw. She was diagnosed as a case of generalized chronic periodontitis. She had undergone periodontal flap therapy as a result of which she complained of gingival recession and black triangles in upper anterior region. Surgical correction to cover the recession and the interdental black triangles was not possible and hence the decision to fabricate a gingival veneer was established. (Figure- 3a,3b)

\section{Fabrication Of Gingival Veneers}

Impression was made using irreversible hydrocolloid material with upper arch. To prevent the impression material from flowing out of the palatal aspect, a wax sheet was molded on the palatal side of the teeth to be treated and to form barrier for each embrasure. After setting, this barrier was trimmed so that the wax only formed a barrier at the palatal undercuts was blocked. Care was taken to record the entire details of the buccal vestibule from canine to canine. This enabled the gingival veneer to fill the inter-dental spaces, so that it reduced lisping by preventing the air to escape from the inter-dental spaces. This also aids in providing additional retention. The tray was carefully fitted and the impression was allowed to set. Then the tray was removed from the mouth carefully so not to tear the inter-dental tags, which represented the embrasure spaces. Cast was obtained and a wax-up was carried out, which was processed in the usual manner as an acrylic removable denture. On completion of curing the veneers was gently removed from the flask, trimmed, finished and polished. The veneer was tried in the mouth and, if necessary, trimmed to remove excess material till an accurate fit is obtained. Patient was instructed to clean the veneer once each day with mild detergent and soft brush. Also instructions were given to clean it every time after having meals. The veneer was to be stored in water during night to prevent shrinkage or distortion of the prosthesis. This would also ensure adequate rest to the gingival tissues. The patient was continuously educated and motivated for persistent plaque control in the ongoing prevention of both caries and periodontal disease was emphasized. ${ }^{[7]}$

\section{Discussion}

Chronic Periodontal disease results in the loss of the bone and supporting tissues. Leading to gingival recession, reduce keratinized tissue height, mobility of the teeth. Unfortunately the successful treatment of chronic periodontitis not only will often lead to gingival recession as a result of shrinkage of flap after healing but also lead to an unaesthetic end result. There are various predictable methods to cover gingival recession, but only in situation of Miller class I and II cases, complete root coverage is possible. To overcome these problems second surgical procedure is time consuming and cause surgical trauma to the patient. In our case series, patients 
with moderate to severe periodontitis were treated with periodontal flap surgical procedure and there was increase in post operative recession and black triangles leading to millers class III and IV recession, where there is no predictable surgical method for correcting esthetic deformities. The only way to improve the esthetics is to try and mask the tissue loss especially in generalized recession situation. The gingival veneer is a viable treatment option for restoring anterior esthetics in clinical situations where there are esthetic concerns caused by significant gingival recession and black triangles. Case selection is an important factor for predictable and successful outcome. ${ }^{[8]}$

Gingival prosthesis takes several forms and various authors have described their uses and methods of construction. ${ }^{[9]}$ Materials used for prosthesis include pink auto cured and heat cured acrylics, porcelains, composite resins, and thermoplastic acrylics as well as silicone based soft materials. Greene PR in $1998^{[8]}$ described two stage impression techniques for construction of two identical veneers. In our study heat cure acrylics were used in all the 3 cases. The gingival prosthesis replaces a large volume of tissue in patients with generalized attachment loss due to periodontal disease. The gingival prosthesis can be easily maintained by the patients and provides good esthetics.

\section{Conclusion}

The gingival veneers are easily constructed, inexpensive, and practical device to optimize the esthetic and functional outcome and where patient do not need to undergo second surgical procedure for recession coverage of denuded roots and black triangles. Thus in the present case series acrylic gingival veneer has been used successfully and after repeated follow-up, the veneers has not produced any problems indicating that such prostheses can be made, can be used use of effectively whenever indicated.

\section{References}

[1]. Cunliffe J, Pretty I. Patients' ranking of interdental "black triangles" against other common aesthetic problems. Eur J Prosthodont Restor Dent 2009; 17:177-81.

[2]. Mekayarajjnanoth T, Kiat-amnuay S, Sooksuntisakoonchai N, Salinas TJ, The functional and esthetic deficit replaced with an acrylic resin gingival veneer, Quintessence International 2002; 33(2):91-94.

[3]. Ellis SGS, Sharma P, Harris IR, Case report: aesthetic management of a localized periodontal defect with a gingival veneer prosthesis, European Journal of Prosthodont Restorative Dentistry 2000; 8(1):23-26.

[4]. Emslie RD, A case of advanced periodontitis complex. Dental Practitioner 1955; 5:432-433.

[5]. L'Estrange PR, Strahan JD, The wearing of acrylic periodontal veneers. British Dental Journal 1970; 128:193-194.

[6]. Hickey B, Jauhar S. Gingival veneers. Dent Update 2009; 36:422- 428.

[7]. Nair C. and Dange SP.: Aesthetic management of gingival recession - A flexible gingival mask. Jour of Indian Prosth Society. 2003; 3(1):34-35.

[8]. Greene PR. The flexible gingival mask: An aesthetic solution in periodontal practice. Br Dent J 1998; 184:536-40.

[9]. Hickey B, Jauhar S. Gingival veneers. Dent Update 2009; 36:422- 428.

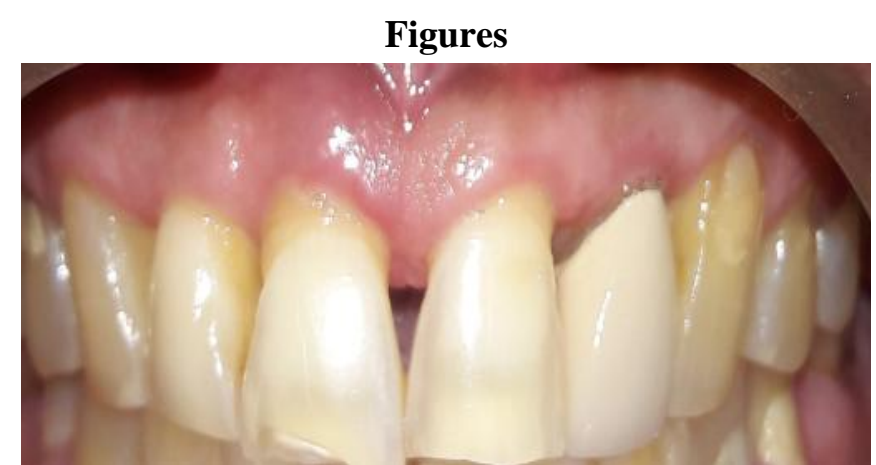

Figure - 1a: After periodontal flap surgical procedure recession with 11,12 and black triangle with 11-21,11-12.

Figure - 1b: After placing gingival veneers

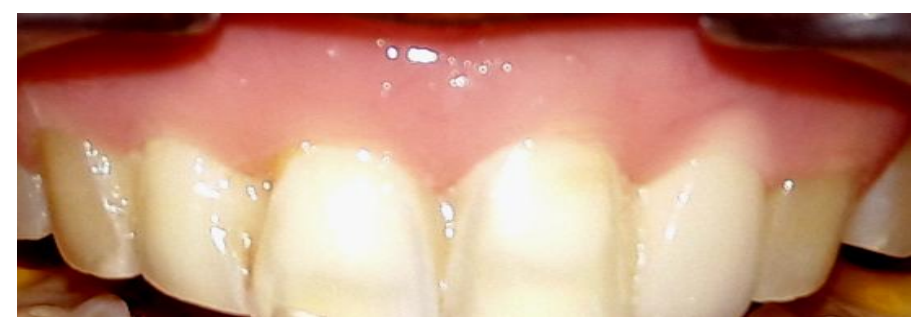

Figure -2a: After periodontal flap surgical procedure recession with 13-23 and black triangle with 11-21, 11-12, $21-22$ 


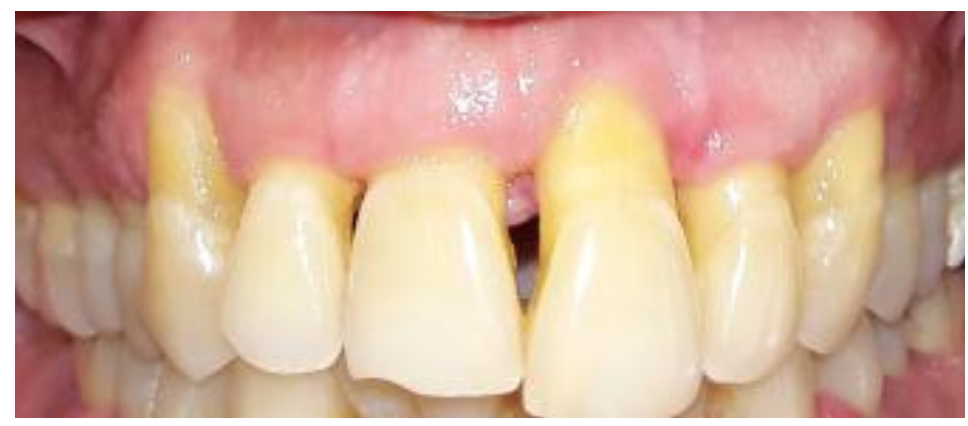

Figure -2b: After placing gingival veneers

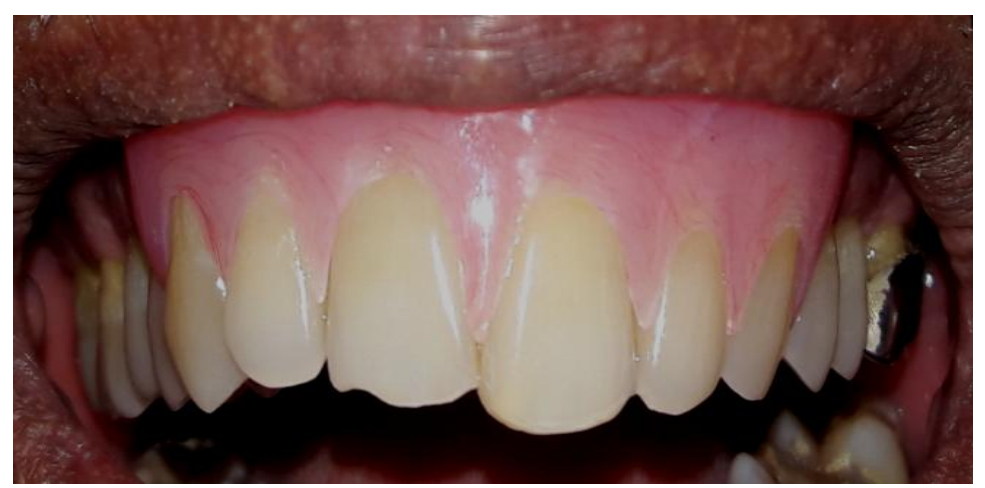

Figure -3a: After periodontal flap surgical procedure recession with 13-23 and black triangle with 11-21, 11-12, $21-22,22-23$

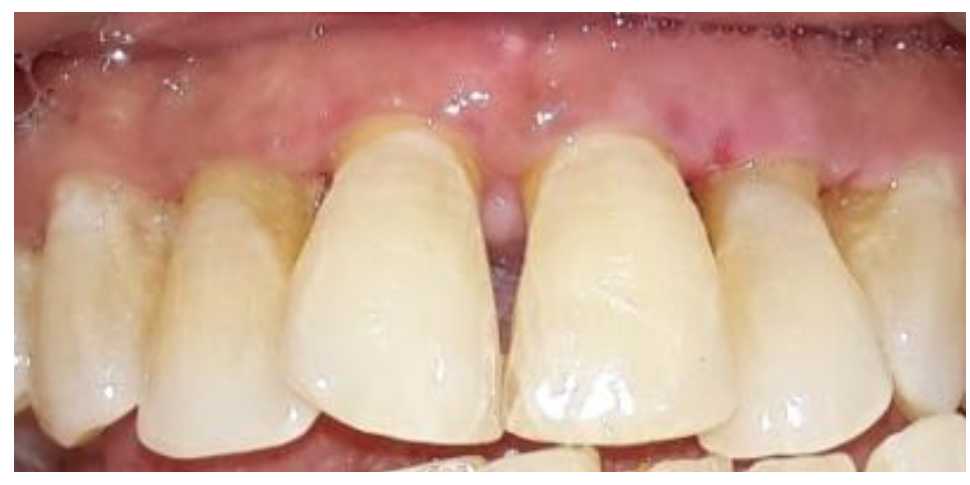

Figure -3b: After placing gingival veneers

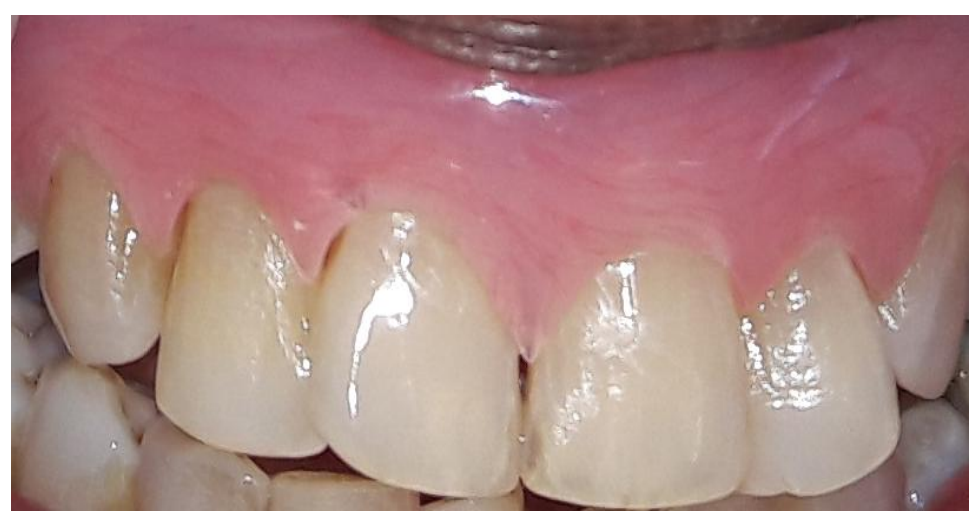

